\title{
Analysis of Risk Factors for Hepatic Sinusoidal Obstruction Syndrome Following Allogeneic Hematopoietic Stem Cell Transplantation in Pediatric Patients
}

\section{Jaspar Kloehn}

Department of Pediatrics, Jena University Hospital, Jena, Germany

\section{Grit Brodt}

Department of Pediatrics, Jena University Hospital, Jena, Germany Jana Ernst

Department of Pediatrics, Jena University Hospital, Jena, Germany Bernd Gruhn ( $\sim$ Bernd.Gruhn@med.uni-jena.de )

Department of Pediatrics, Jena University Hospital, Jena, Germany https://orcid.org/0000-0003-18620075

\section{Research Article}

Keywords: Allogeneic hematopoietic stem cell transplantation, Sinusoidal obstruction syndrome, Children, Risk factors, INR

Posted Date: March 31st, 2021

DOl: https://doi.org/10.21203/rs.3.rs-374214/v1

License: (c) (1) This work is licensed under a Creative Commons Attribution 4.0 International License. Read Full License

Version of Record: A version of this preprint was published at Journal of Cancer Research and Clinical Oncology on July 13th, 2021. See the published version at https://doi.org/10.1007/s00432-021-03732-1. 


\section{Abstract}

Purpose Hepatic sinusoidal obstruction syndrome (SOS), which is also known as veno-occlusive disease of the liver, represents a serious complication following hematopoietic stem cell transplantation (HSCT). Our study aimed to investigate important risk factors for SOS in a pediatric population.

Methods This retrospective study analyzed 105 children who underwent allogeneic HSCT at our pediatric HSCT center in Jena. The observation period was 12 years and SOS was defined by the modified pediatric Seattle criteria up to day +30 after HSCT.

Results 15 out of all 105 patients developed SOS (14.3\%). The median time from HSCT to SOS diagnosis was 12 days. The mortality rate of SOS was only $20.0 \%$. In univariate analysis, we identified the significant risk factors of a patient age $<1$ year (odds ratio $(\mathrm{OR})=7.25, p=0.037$ ) and a prior treatment with gemtuzumab ozogamicin $(\mathrm{OR}=11.00, p=0.020)$. In addition, some laboratory values, which were taken before HSCT, had a significant association to SOS. Ferritin $>1500 \mathrm{ng} / \mathrm{mL}(\mathrm{OR}=4.00, p=0.033)$, ferritin $>2000 \mathrm{ng} / \mathrm{mL}(\mathrm{OR}=4.69, p=0.016)$, ferritin $>2400 \mathrm{ng} / \mathrm{mL}(\mathrm{OR}=5.29, p=0.005)$ and the international normalized ratio $(\mathrm{INR}) \geq 1.3(\mathrm{OR}=5.91, p=0.009)$ showed significant results in univariate analysis. The following risk factors could be confirmed in multivariate analysis: prior treatment with gemtuzumab ozogamicin (OR $=9.24, p=0.048)$, ferritin $>2400 \mathrm{ng} / \mathrm{mL}(\mathrm{OR}=5.74, p=0.023)$ and $\mathrm{INR} \geq$ $1.3(\mathrm{OR}=8.02, p=0.007)$.

Conclusion Our study confirms several risk factors for hepatic SOS following allogeneic HSCT in pediatric patients. In addition, we report for the first time a significant association between high INR before HSCT and hepatic SOS, which consequently could improve the SOS risk evaluation.

\section{Introduction}

Hepatic sinusoidal obstruction syndrome (SOS), previously called veno-occlusive disease (VOD), is one of the potentially life-threatening complications following hematopoietic stem cell transplantation (HSCT).

Pathophysiologically, initial damage to the sinusoidal endothelium leads to an activation of endothelial cells (DeLeve et al. 1999; DeLeve et al. 2002). This damage is caused by factors like chemotherapy or radiotherapy as part of the conditioning regimen before HSCT. The unregulated endothelial activation results in a loss of sinusoidal barrier, leading to extravasation of erythrocytes, leukocytes and cellular debris into the space of Disse. Moreover, a cascade of thrombotic and antithrombotic effects causes a hemostatic dysbalance. The damaged sinusoids induce a downstream embolization, sinusoidal obstruction, and occlusion of terminal hepatic venules (Carreras and Diaz-Ricart 2011; Coppell et al. 2003; Mohty et al. 2015).

The frequency of SOS varies widely in the published literature depending on different diagnostic criteria (Carreras et al. 2011; Coppell et al. 2010; Kammersgaard et al. 2019). Coppell et al. (2010) showed a mean incidence of $13.7 \%$ for SOS following HSCT by analyzing different reports of SOS occurring with a 
range from $0-62 \%$. Traditional diagnostic standards are based on the Baltimore criteria, reported by Jones et al. (1987), or the Seattle criteria, reported by McDonald et al. (1984). The Seattle criteria have been modified several times. The modified pediatric Seattle criteria, attributed to Corbacioglu et al. (2012), are presented in Table 1 . These citeria depend on the clinical findings hyperbilirubinemia $(>34 \mu \mathrm{mol} / \mathrm{L} ;>2$ $\mathrm{mg} / \mathrm{dL})$ ), hepatomegaly, ascites and unexplained weight gain (>5\%) (Corbacioglu et al. 2012). Recently, new diagnostic criteria have been published on behalf of the European Society for Blood and Marrow Transplantation (EBMT) to achieve an earlier identification and to detect late-onset SOS. Mohty et al. (2016) developed the EBMT criteria for SOS in adult patients. Furthermore, Corbacioglu et al. (2018) published the pediatric EBMT criteria. In addition to the EBMT criteria, Cairo et al. (2020) proposed modified diagnostic criteria. In the past years, different criteria for severity grading were published (Bearman et al. 1993; Cairo et al. 2020; Corbacioglu et al. 2018; McDonald et al. 1993; Mohty et al. 2016). In common the most severe form of SOS can lead to multi-organ dysfunction with a mortality rate of up to $84 \%$ (Coppell et al. 2010).

The most promising therapeutic option for SOS is the use of defibrotide, which was shown in several studies for both adult and pediatric patients (Chopra et al. 2000; Corbacioglu et al. 2004; Locatelli et al. 2020; Richardson et al. 1998; Richardson et al. 2002; Richardson et al. 2016; Richardson et al. 2013). Additionally, the prophylactic effect of defibrotide was described (Corbacioglu et al. 2012; Qureshi et al. 2008).

The known risk factors for SOS can be classified into patient-related factors and transplantation-related factors (Corbacioglu et al. 2019; Dalle and Giralt 2016). Patient-related factors include young patient age, preexisting liver disease, advanced malignant underlying diseases, treatment with gemtuzumab ozogamicin, high transaminase levels, high serum ferritin and genetic factors (Carreras et al. 1998; Cheuk et al. 2007; Maximova et al. 2014; McDonald 2002; Morado et al. 1999; Seifert et al. 2015). Reported transplantation-related risk factors are allogeneic HSCT, conditioning regimen based on busulfan, cyclophosphamide, fludarabine or total body irradiation and unrelated donors (Barker et al. 2003; Carreras et al. 1998; Carreras et al. 2011).

Even though some risk factors are already known, it is important to confirm these results and to analyze new potential risk factors. This will lead to better risk stratification and earlier identification of SOS. The purpose of our study was to evaluate the risk factors of SOS in pediatric patients undergoing allogeneic HSCT.

\section{Patients And Methods}

\section{Patients}

Our retrospective study included 105 children, adolescents and young adults who underwent allogeneic HSCT at the Department of Pediatrics of Jena University Hospital in Germany. We only analyzed recipients after the first HSCT. Patients who received a defibrotide prophylaxis were excluded. The transplantations were performed between January 2007 and December 2018. All patients underwent a 
myeloablative conditioning regimen and were nursed in single rooms with a laminar airflow filtration system.

\section{Definitions}

SOS was defined by using the modified pediatric Seattle criteria up to day +30 after HSCT (Corbacioglu et al. 2012). These criteria include hyperbilirubinemia ( $>34 \mu \mathrm{mol} / \mathrm{L} ;>2 \mathrm{mg} / \mathrm{dL}$ ), hepatomegaly, ascites and unexplained weight gain ( $>5 \%)$. The diagnosis of SOS was confirmed when at least two of the mentioned criteria were met within 30 days after HSCT. The classification of the severity of SOS was based on the severity criteria by McDonald et al. (1993) in consideration of later modifications. SOS was defined as mild when patients had no apparent adverse effect from SOS, did not need diuretic or analgesic therapy, and showed completely reversible clinical and laboratory abnormalities. The moderate stage was characterized by clinical worsening following SOS or the need for diuretic or analgesic therapy. Patients with moderate SOS showed a full recovery within 100 days. Any clinical worsening without recovery within 100 days, as well as the occurrence of multiple organ failure or even death, was classified as severe SOS.

\section{Risk factors}

In our study, we considered patient-related factors, including several laboratory parameters, and transplantation-related factors. Some analyzed factors were already known to be associated with SOS. Moreover, we investigated new potential risk factors. The following transplantation-related factors were included in our study: conditioning regimen based on busulfan, cyclophosphamide, melphalan or total body irradiation, graft source, donor age, donor sex and donor-recipient human leukocyte antigen (HLA)match. In addition, we explored the following patient-related factors: patient age, patient sex, prior treatment with gemtuzumab ozogamicin as well as the laboratory parameters of aspartate transaminase, alanine transaminase, cholinesterase, glutamyl transpeptidase, lactate dehydrogenase, alkaline phosphatase, ferritin, albumin, total bilirubin, C-reactive protein and international normalized ratio (INR). All laboratory values were determined before HSCT. Furthermore, cutoffs were chosen for metric variables such as age and laboratory parameters. These cutoffs were defined by reference values, clinical consideration and receiver operating characteristic (ROC) curve analysis.

\section{Statistical analysis}

To evaluate the association between the analyzed factors and the occurrence of SOS, univariate and multivariate analyses were performed. $P$-values of less than 0.05 indicated statistical significance. The results for each variable were expressed as odds ratios (OR) with their $95 \%$ confidence intervals $(\mathrm{Cl})$. ROC curve analysis was used to determine adequate cutoffs. Univariate analyses were carried out by chisquare test or Fisher's exact test. Moreover, the Mann-Whitney U-test was used to compare the median values of metric variables. Variables that were significant in the univariate analyses were entered into multivariate analysis. The multivariate analysis was performed by backward stepwise logistic regression. All calculations were performed by the software IBM SPSS Statistics 26. 


\section{Results}

\section{Patient characteristics}

The characteristics of the 105 patients are presented in Table 2. The study population consisted of 61 males and 44 females with a median age of 8.6 years (ranged from 0 to 26 years). Either bone marrow ( $\mathrm{n}$ $=74)$ or peripheral blood $(n=31)$ was used as stem cell source. The most frequent underlying diseases were acute lymphoblastic leukemia $(n=27)$, acute myeloid leukemia $(n=25)$ and genetic disease $(n=25)$.

\section{Incidence and mortality of SOS}

SOS occurred in 15 out of 105 transplantations (14.3\%). The median time of the SOS diagnosis was 12 days after HSCT (range 1-26 days). Mild SOS occurred in 3 cases, moderate SOS in 4 cases, while 8 patients showed a severe form. Among the 15 patients with SOS, 3 subsequently died (20.0\%). These 3 patients died within the first 100 days after HSCT. In contrast, 5 out of 90 patients without the diagnosis of SOS died in this period, which results in a 100-day mortality of only $5.6 \%$.

\section{Analysis of risk factors}

The Tables 3 and 4 display the univariate analysis of transplantation-related and patient-related factors. We could not find any significant association between transplantation-related factors and the occurrence of SOS. However, several significant patient-related risk factors could be identified in our study. Patients aged less than 1 year had a significantly higher rate of SOS compared to older patients (50.0\% vs. $12.1 \%$, $\mathrm{OR}=7.25, p=0.037$ ). Additionally, prior treatment with gemtuzumab ozogamicin was significantly associated with the incidence of SOS $(O R=11.00, p=0.020)$. The SOS rate in patients treated with gemtuzumab ozogamicin was $60.0 \%$ compared to $12.0 \%$ in the group without such treatment. By comparing the pretransplant serum levels of ferritin in patients with and without SOS, a significantly higher median ferritin was found in patients who developed SOS $(2816.9 \mathrm{ng} / \mathrm{mL}$ vs. $1554.0 \mathrm{ng} / \mathrm{mL}, p=$ 0.026). Different cutoffs for serum ferritin were analyzed by a ROC curve (Fig. 1). A cutoff value of $2420.15 \mathrm{ng} / \mathrm{mL}$ (see arrow in Fig. 1) indicated the best result for sensitivity $(73.3 \%)$ and specificity (65.8\%). To put this cutoff into clinical practice, it was rounded to a value of $2400 \mathrm{ng} / \mathrm{mL}$. Patients with serum ferritin $>2400 \mathrm{ng} / \mathrm{mL}$ showed a significantly higher incidence of SOS compared to those with ferritin $\leq 2400 \mathrm{ng} / \mathrm{mL}(29.7 \%$ vs. $7.4 \%, O R=5.29, p=0.005)$. Furthermore, ferritin $>1500 \mathrm{ng} / \mathrm{mL}$ (OR = $4.00, p=0.033)$ and ferritin $>2000 \mathrm{ng} / \mathrm{mL}(\mathrm{OR}=4.69, p=0.016)$ were significant risk factors. I addition, we noted a significant correlation between pretransplant INR $\geq 1.3$ and the occurrence of SOS $(O R=5.91$, $p=0.009$ ). Patients with INR $\geq 1.3$ showed a SOS rate of $37.5 \%$. In contrast, the SOS rate was $9.2 \%$ in patients with lower INR.

As presented in Table 5, the following factors were significant in our multivariate analysis: prior treatment with gemtuzumab ozogamicin (OR $=9.24, p=0.048)$, ferritin $>2400 \mathrm{ng} / \mathrm{mL}(\mathrm{OR}=5.74, p=0.023)$ and INR $\geq 1.3(\mathrm{OR}=8.02, p=0.007)$. 


\section{Discussion}

In our study, 15 out of 105 patients developed SOS. Consequently, the incidence of SOS was $14.3 \%$. In a previous study, which compared different incidence rates of SOS across several studies an overall mean incidence of $13.7 \%$ was reported (Coppell et al. 2010). This demonstrates that our result is consistent with previous data. In our study population, the median time of SOS onset was 12 days after HSCT, which corresponds to the literature. Yakushijin et al. (2016) retrospectively analyzed 4290 patients who underwent allogeneic HSCT. In that study, the median time of SOS diagnosis was also 12 days postHSCT (Yakushijin et al. 2016). The frequencies of mild, moderate and severe SOS have been variously reported. From all patients with SOS, we observed a relative distribution of $20.0 \%$ mild, $26.7 \%$ moderate and $53.3 \%$ severe disease courses. In a study published by Cheuk et al. (2007), 47.4\% had mild SOS, $21.1 \%$ had moderate SOS and $31.6 \%$ had severe SOS. However, Maximova et al. (2014) reported a rate of $12.0 \%$ mild, $12.0 \%$ moderate and $76.0 \%$ severe courses of SOS. In all cases, the same criteria for severity grading based on McDonald et al. (1993) were used. Furthermore, all studies only included pediatric patients. This variation can be explained by a different interpretation of the severity grading criteria or small case numbers. In the present study, the mortality rate from SOS was only $20.0 \%$, which is a lower rate, especially compared to previous studies (Barker et al. 2003; Cheuk et al. 2007; Jones et al. 1987; McDonald et al. 1993). The lower mortality rates in recent studies are probably due to the early treatment with defibrotide (Corbacioglu et al. 2016; Faraci et al. 2019; Mohty et al. 2020; Richardson et al. 2017).

The diagnosis of SOS was based on the modified pediatric Seattle criteria according to Corbacioglu et al. (2012). In recent years, new diagnostic criteria have been published (Cairo et al. 2020; Corbacioglu et al. 2018; Mohty et al. 2016). Additionally, new severity criteria were proposed. In our study, we decided not to use these new criteria because nearly all transplantations had been performed before the new pediatric EBMT criteria were published (Corbacioglu et al. 2018). By using the new EBMT criteria, the number of diagnosed SOS cases would be probably higher, especially due to no limitation for the time of SOS onset (Kammersgaard et al. 2019). Therefore, we preferred a consistent use of the modified pediatric Seattle criteria.

Previous publications have already shown significant associations between the transplantation-related factors of conditioning regimen based on busulfan or total body irradiation and the occurrence of SOS (Barker et al. 2003; Carreras et al. 1998; Cheuk et al. 2007; Yakushijin et al. 2016). On the contrary, these reported risk factors were not found to be significant in our study. One reason for this result can be the limited number of analyzed patients. Nevertheless, other studies also could not find a significant correlation (Kami et al. 1997; Maximova et al. 2014).

A significant relationship between an increased risk of SOS and donor mismatch has already been reported (Hasegawa et al. 1998). We could not confirm this finding in our patient population. Other transplantation-related factors like stem cell source, donor age and donor sex were not significantly associated with the incidence of SOS either. Carreras et al. (2011) showed a significantly higher rate of SOS in transplantations with bone marrow stem cells compared to transplantations with peripheral blood 
stem cells. A few other analyses could not find a significant correlation between the stem cell source and the development of SOS (Cheuk et al. 2007; Faraci et al. 2019; Soyer et al. 2020; Strouse et al. 2018). In future trials, this potential risk factor should be further explored.

With regards to younger patients, we found that an age $<1$ year had a significant impact on the development of SOS in the univariate analysis $(p=0.037)$. Full hepatic maturation takes up to 2 years after birth (Beath 2003). This demonstrates that infants have a reduced hepatic detoxification function, which consequently makes them particularly vulnerable to the conditioning regimen. Thus, higher rates of SOS could be explained. Moreover, pediatric diseases that are predisposing to SOS are found more often in the first years of life (Cesaro et al. 2005). This especially applies to neuroblastoma. Our findings concur with the published literature although different cutoffs for age were proposed (Cesaro et al. 2005; Cheuk et al. 2007; Faraci et al. 2019).

In our study, we could not find a significant correlation between female sex and the incidence of SOS. According to our results, this factor was not listed in some detailed reviews (Cairo et al. 2020; Dalle and Giralt 2016). However, other studies identified female sex as a significant risk factor (Faraci et al. 2019; Hägglund et al. 1998). This aspect should be further investigated in future trials.

Previous reports have already highlighted the treatment with gemtuzumab ozogamicin as a risk factor for SOS incidence (McDonald 2002; Richardson and Corbacioglu 2020; Wadleigh et al. 2003). It is assumed that gemtuzumab ozogamicin targets CD33 + cells in the hepatic sinusoids, such as Kupffer cells, stellate cells and endothelial cells (Rajvanshi et al. 2002). Our study confirms the significant risk factor of prior treatment with gemtuzumab ozogamicin for the pediatric population in univariate analysis $(p=0.020)$ as well as in multivariate analysis $(p=0.048)$.

In the literature, some studies showed significant correlations between SOS and elevated values of aspartate transaminase, alanine transaminase and total bilirubin as well as reduced values of cholinesterase and albumin (Carreras et al. 1998; Hägglund et al. 1998; Hasegawa et al. 1998; Srivastava et al. 2004). These values indicate preexisting liver damage. However, we could not find such significant associations in our patient population. According to the current state of relevant studies, the laboratory parameters of glutamyl transpeptidase, lactate dehydrogenase, alkaline phosphatase, C-reactive protein were not significant risk factors (Cairo et al. 2020; Corbacioglu et al. 2019; Dalle and Giralt 2016; Morado et al. 1999). In regard to serum ferritin, we detected significantly higher SOS rates in patients with ferritin $>1500 \mathrm{ng} / \mathrm{mL},>2000 \mathrm{ng} / \mathrm{mL}$ and $>2400 \mathrm{ng} / \mathrm{mL}$. However, $>2400 \mathrm{ng} / \mathrm{mL}$ was the optimal cutoff with $p=$ 0.005 in univariate analysis and $p=0.023$ in multivariate analysis. High serum ferritin indicates iron overload, which is considered to be a reason for liver dysfunction (McKay et al. 1996; Miceli et al. 2006). Iron induces the development of oxygen free radicals that lead to an injury of hepatic tissue (Ramm and Ruddell 2005). Additionally, high serum ferritin can be explained by the response to inflammation through its role as an acute-phase protein (Armand et al. 2012). It can be suggested that these factors predispose to SOS. Our findings accord with other studies (Maradei et al. 2009; Maximova et al. 2014; Morado et al. 1999). 
In our study, we report for the first time that high pretransplant INR was significantly associated with the occurrence of SOS. The cutoff of $\geq 1.3$ was significant in univariate analysis $(p=0.009)$ as well as in multivariate analysis $(p=0.007)$. Higher INR values indicate increased bleeding tendency (Kirkwood 1983). Although SOS is characterized by downstream embolization and sinusoidal obstruction, there is an initial hemorrhage of erythrocytes, leukocytes and cellular debris into the spaces of Disse (Carreras and Diaz-Ricart 2011; Mohty et al. 2015). Therfore, an increased bleeding tendency, measured by high INR, could lead to a higher risk of SOS. Moreover, INR is affected by vitamin K-dependent coagulation factors (Tripodi et al. 1995). High INR can be caused by a lack of coagulation factors, which is linked with liver dysfunction. This is another reason why high INR might be correlated to SOS.

Our study is limited by the relatively small number of patients, which leads to reduced statistical power. However, the rather small number of patients is quite common in single-center studies with only pediatric patients. I addition, our study is a retrospective analysis which is more susceptible to observation and selection biases compared to prospective studies. Nevertheless, the inclusion criteria were clearly defined and consistently used.

In conclusion, our findings confirm the risk factors of young patient age ( $<1$ year), prior treatment with gemtuzumab ozogamicin and high serum ferritin $(>2400 \mathrm{ng} / \mathrm{mL})$ for the occurrence of hepatic SOS in the pediatric population. Furthermore, the significant association between high pretransplant INR $(\geq 1.3)$ and the development of SOS is reported for the first time. Our findings can contribute to a better risk stratification and a modified screening system after allogeneic HSCT in pediatric patients. Finally, further studies are necessary to validate our findings. This especially applies to the new risk factor of high INR.

\section{Declarations}

\section{Compliance with ethical standards}

Conflict of interest The authors declare no potential conflict of interest.

Ethical standard All procedures were in accordance with the ethical standards. The study was approved by the ethics committee at the University Hospital of the Friedrich Schiller University at Jena (2021-2060). Informed consent was obtained from all individual participants or the responsible persons included in the study.

\section{References}

1. Armand P et al. (2012) Does iron overload really matter in stem cell transplantation? Am J Hematol 87:569-572 doi:10.1002/ajh.23188

2. Barker CC, Butzner JD, Anderson RA, Brant R, Sauve RS (2003) Incidence, survival and risk factors for the development of veno-occlusive disease in pediatric hematopoietic stem cell transplant recipients Bone Marrow Transplantation 32:79-87 doi:10.1038/sj.bmt.1704069 
3. Bearman SI, Anderson GL, Mori M, Hinds MS, Shulman HM, McDonald GB (1993) Venoocclusive disease of the liver: development of a model for predicting fatal outcome after marrow transplantation J Clin Oncol 11:1729-1736 doi:10.1200/jco.1993.11.9.1729

4. Beath SV (2003) Hepatic function and physiology in the newborn Semin Neonatol 8:337-346 doi:10.1016/s1084-2756(03)00066-6

5. Cairo MS, Cooke KR, Lazarus HM, Chao N (2020) Modified diagnostic criteria, grading classification and newly elucidated pathophysiology of hepatic SOS/VOD after haematopoietic cell transplantation $\mathrm{Br} J$ Haematol doi:10.1111/bjh.16557

6. Carreras E et al. (1998) Incidence and outcome of hepatic veno-occlusive disease after blood or marrow transplantation: a prospective cohort study of the European Group for Blood and Marrow Transplantation Blood, The Journal of the American Society of Hematology 92:3599-3604

7. Carreras E, Díaz-Beyá M, Rosiñol L, Martínez C, Fernández-Avilés F, Rovira M (2011) The incidence of veno-occlusive disease following allogeneic hematopoietic stem cell transplantation has diminished and the outcome improved over the last decade Biology of blood and marrow transplantation $17: 1713-1720$

8. Carreras E, Diaz-Ricart M (2011) The role of the endothelium in the short-term complications of hematopoietic SCT Bone Marrow Transplant 46:1495-1502 doi:10.1038/bmt.2011.65

9. Cesaro $S$ et al. (2005) A prospective survey on incidence, risk factors and therapy of hepatic venoocclusive disease in children after hematopoietic stem cell transplantation haematologica 90:13961404

10. Cheuk DKL, Wang P, Lee TL, Chiang AKS, Ha SY, Lau YL, Chan GCF (2007) Risk factors and mortality predictors of hepatic veno-occlusive disease after pediatric hematopoietic stem cell transplantation Bone Marrow Transplantation 40:935-944 doi:10.1038/sj.bmt.1705835

11. Chopra R et al. (2000) Defibrotide for the treatment of hepatic veno-occlusive disease: results of the European compassionate-use study British journal of haematology 111:1122-1129

12. Coppell JA, Brown SA, Perry DJ (2003) Veno-occlusive disease: cytokines, genetics, and haemostasis Blood Rev 17:63-70 doi:10.1016/s0268-960x(03)00002-x

13. Coppell JA et al. (2010) Hepatic veno-occlusive disease following stem cell transplantation: incidence, clinical course, and outcome Biol Blood Marrow Transplant 16:157-168 doi:10.1016/j.bbmt.2009.08.024

14. Corbacioglu $S$ et al. (2018) Diagnosis and severity criteria for sinusoidal obstruction syndrome/venoocclusive disease in pediatric patients: a new classification from the European society for blood and marrow transplantation Bone Marrow Transplant 53:138-145 doi:10.1038/bmt.2017.161

15. Corbacioglu $S$ et al. (2016) Defibrotide for the treatment of hepatic veno-occlusive disease: final results from the international compassionate-use program Biology of Blood and Marrow Transplantation 22:1874-1882

16. Corbacioglu S et al. (2012) Defibrotide for prophylaxis of hepatic veno-occlusive disease in paediatric haemopoietic stem-cell transplantation: an open-label, phase 3, randomised controlled 
trial Lancet 379:1301-1309 doi:10.1016/s0140-6736(11)61938-7

17. Corbacioglu $S$ et al. (2004) Defibrotide in the treatment of children with veno-occlusive disease (VOD): a retrospective multicentre study demonstrates therapeutic efficacy upon early intervention Bone marrow transplantation 33:189-195

18. Corbacioglu S, Jabbour EJ, Mohty M (2019) Risk Factors for Development of and Progression of Hepatic Veno-Occlusive Disease/Sinusoidal Obstruction Syndrome Biol Blood Marrow Transplant 25:1271-1280 doi:10.1016/j.bbmt.2019.02.018

19. Dalle J-H, Giralt SA (2016) Hepatic veno-occlusive disease after hematopoietic stem cell transplantation: risk factors and stratification, prophylaxis, and treatment Biology of Blood and Marrow Transplantation 22:400-409

20. DeLeve LD, McCuskey RS, Wang X, Hu L, McCuskey MK, Epstein RB, Kanel GC (1999) Characterization of a reproducible rat model of hepatic veno-occlusive disease Hepatology 29:17791791 doi:10.1002/hep. 510290615

21. DeLeve LD, Shulman HM, McDonald GB (2002) Toxic injury to hepatic sinusoids: sinusoidal obstruction syndrome (veno-occlusive disease) Semin Liver Dis 22:27-42 doi:10.1055/s-2002-23204

22. Faraci M et al. (2019) Sinusoidal obstruction syndrome/Veno-occlusive disease after autologous or allogeneic hematopoietic stem cell transplantation in children: a retrospective study of the Italian Hematology-Oncology Association-Hematopoietic Stem Cell Transplantation Group Biology of Blood and Marrow Transplantation 25:313-320

23. Hägglund $H$, Remberger $M$, Klaesson S, Lönnqvist B, Ljungman P, Ringdén $O$ (1998) Norethisterone treatment, a major risk-factor for veno-occlusive disease in the liver after allogeneic bone marrow transplantation Blood 92:4568-4572

24. Hasegawa S, Horibe K, Kawabe T, Kato K, Kojima S, Matsuyama T, Hirabayashi N (1998) Venoocclusive disease of the liver after allogeneic bone marrow transplantation in children with hematologic malignancies: incidence, onset time and risk factors Bone Marrow Transplantation 22:1191-1197 doi:10.1038/sj.bmt.1701506

25. Jones RJ et al. (1987) Venoocclusive disease of the liver following bone marrow transplantation Transplantation 44:778-783 doi:10.1097/00007890-198712000-00011

26. Kami M et al. (1997) Risk factors for hepatic veno-occlusive disease after bone marrow transplantation: retrospective analysis of 137 cases at a single institution Bone Marrow Transplantation 20:397-402 doi:10.1038/sj.bmt.1700895

27. Kammersgaard MB, Kielsen K, Heilmann C, Ifversen M, Müller K (2019) Assessment of the proposed EBMT pediatric criteria for diagnosis and severity grading of sinusoidal obstruction syndrome Bone Marrow Transplantation 54:1406-1418 doi:10.1038/s41409-018-0426-8

28. Kirkwood TB (1983) Calibration of reference thromboplastins and standardisation of the prothrombin time ratio Thromb Haemost 49:238-244

29. Locatelli F et al. (2020) Treatment Duration, Symptom Resolution, and Survival in Defibrotide-Treated Patients with Veno-Occlusive Disease/Sinusoidal Obstruction Syndrome after Hematopoietic Cell 
Transplantation: Analysis of a Multinational, Prospective, Observational Registry Study Blood 136:32-33 doi:10.1182/blood-2020-136670

30. Maradei SC, Maiolino A, de Azevedo AM, Colares M, Bouzas LF, Nucci M (2009) Serum ferritin as risk factor for sinusoidal obstruction syndrome of the liver in patients undergoing hematopoietic stem cell transplantation Blood, The Journal of the American Society of Hematology 114:1270-1275

31. Maximova $\mathrm{N}$ et al. (2014) Experience from a single paediatric transplant centre with identification of some protective and risk factors concerning the development of hepatic veno-occlusive disease in children after allogeneic hematopoietic stem cell transplant International journal of hematology 99:766-772

32. McDonald GB (2002) Management of hepatic sinusoidal obstruction syndrome following treatment with gemtuzumab ozogamicin (Mylotarg®) Clinical lymphoma 2:S35-S39

33. McDonald GB et al. (1993) Veno-occlusive disease of the liver and multiorgan failure after bone marrow transplantation: a cohort study of 355 patients Ann Intern Med 118:255-267 doi:10.7326/0003-4819-118-4-199302150-00003

34. McDonald GB, Sharma P, Matthews DE, Shulman HM, Thomas ED (1984) Venocclusive disease of the liver after bone marrow transplantation: diagnosis, incidence, and predisposing factors Hepatology 4:116-122 doi:10.1002/hep.1840040121

35. McKay P, Murphy J, Cameron S, Burnett A, Campbell M, Tansey P, Franklin I (1996) Iron overload and liver dysfunction after allogeneic or autologous bone marrow transplantation Bone marrow transplantation 17:63-66

36. Miceli M et al. (2006) Iron overload is a major risk factor for severe infection after autologous stem cell transplantation: a study of 367 myeloma patients Bone marrow transplantation 37:857-864

37. Mohty M et al. (2020) Prophylactic, preemptive, and curative treatment for sinusoidal obstruction syndrome/veno-occlusive disease in adult patients: a position statement from an international expert group Bone marrow transplantation 55:485-495

38. Mohty M et al. (2016) Revised diagnosis and severity criteria for sinusoidal obstruction syndrome/veno-occlusive disease in adult patients: a new classification from the European Society for Blood and Marrow Transplantation Bone Marrow Transplant 51:906-912 doi:10.1038/bmt.2016.130

39. Mohty M et al. (2015) Sinusoidal obstruction syndrome/veno-occlusive disease: current situation and perspectives-a position statement from the European Society for Blood and Marrow Transplantation (EBMT) Bone Marrow Transplantation 50:781-789 doi:10.1038/bmt.2015.52

40. Morado $M$ et al. (1999) Serum ferritin as risk factor for veno-occlusive disease of the liver. Prospective cohort study Hematology 4:505-512

41. Qureshi A, Marshall L, Lancaster D (2008) Defibrotide in the prevention and treatment of venoocclusive disease in autologous and allogeneic stem cell transplantation in children Pediatr Blood Cancer 50:831-832 doi:10.1002/pbc.21425 
42. Rajvanshi P, Shulman HM, Sievers EL, McDonald GB (2002) Hepatic sinusoidal obstruction after gemtuzumab ozogamicin (Mylotarg) therapy Blood, The Journal of the American Society of Hematology 99:2310-2314

43. Ramm GA, Ruddell RG (2005) Hepatotoxicity of iron overload: mechanisms of iron-induced hepatic fibrogenesis Semin Liver Dis 25:433-449 doi:10.1055/s-2005-923315

44. Richardson PG, Corbacioglu S (2020) Veno-occlusive disease/sinusoidal obstruction syndrome in patients with prior gemtuzumab ozogamicin: literature analysis of survival after defibrotide treatment Blood Cancer Journal 10:29 doi:10.1038/s41408-020-0286-5

45. Richardson PG et al. (1998) Treatment of severe veno-occlusive disease with defibrotide: compassionate use results in response without significant toxicity in a high-risk population Blood 92:737-744

46. Richardson PG et al. (2002) Multi-institutional use of defibrotide in 88 patients after stem cell transplantation with severe veno-occlusive disease and multisystem organ failure: response without significant toxicity in a high-risk population and factors predictive of outcome Blood 100:4337-4343 doi:10.1182/blood-2002-04-1216

47. Richardson PG et al. (2016) Phase 3 trial of defibrotide for the treatment of severe veno-occlusive disease and multi-organ failure Blood 127:1656-1665 doi:10.1182/blood-2015-10-676924

48. Richardson PG et al. (2017) Defibrotide for patients with hepatic veno-occlusive disease/sinusoidal obstruction syndrome: interim results from a treatment IND study Biology of blood and marrow transplantation 23:997-1004

49. Richardson PG et al. (2013) Results Of The Large Prospective Study On The Use Of Defibrotide (DF) In The Treatment Of Hepatic Veno-Occlusive Disease (VOD) In Hematopoietic Stem Cell Transplant (HSCT). Early Intervention Improves Outcome - Updated Results Of a Treatment IND (T-IND) Expanded Access Protocol Blood 122:700-700 doi:10.1182/blood.V122.21.700.700

50. Seifert C, Wittig S, Arndt C, Gruhn B (2015) Heparanase polymorphisms: influence on incidence of hepatic sinusoidal obstruction syndrome in children undergoing allogeneic hematopoietic stem cell transplantation J Cancer Res Clin Oncol 141:877-885 doi:10.1007/s00432-014-1857-2

51. Soyer $\mathbf{N}$ et al. (2020) Incidence and risk factors for hepatic sinusoidal obstruction syndrome after allogeneic hematopoietic stem cell transplantation: a retrospective multicenter study of Turkish Hematology Research and Education Group (ThREG) Transfusion and Apheresis Science:102827

52. Srivastava A, Poonkuzhali B, Shaji RV, George B, Mathews V, Chandy M, Krishnamoorthy R (2004) Glutathione S-transferase M1 polymorphism: a risk factor for hepatic venoocclusive disease in bone marrow transplantation Blood 104:1574-1577

53. Strouse $C$ et al. (2018) Risk score for the development of veno-occlusive disease after allogeneic hematopoietic cell transplant Biology of Blood and Marrow Transplantation 24:2072-2080

54. Tripodi A, Chantarangkul V, Akkawat B, Clerici M, Mannucci PM (1995) A partial factor V deficiency in anticoagulated lyophilized plasmas has been identified as a cause of the international normalized 
ratio discrepancy in the external quality assessment scheme Thromb Res 78:283-292

doi:10.1016/0049-3848(95)00061-u

55. Wadleigh $\mathrm{M}$ et al. (2003) Prior gemtuzumab ozogamicin exposure significantly increases the risk of veno-occlusive disease in patients who undergo myeloablative allogeneic stem cell transplantation Blood 102:1578-1582

56. Yakushijin K et al. (2016) Sinusoidal obstruction syndrome after allogeneic hematopoietic stem cell transplantation: Incidence, risk factors and outcomes Bone Marrow Transplantation 51:403-409 doi:10.1038/bmt.2015.283

\section{Tables}

Table 1

Modified pediatric Seattle criteria for the diagnosis of SOS

\begin{tabular}{|l|}
\hline Modified Seattle criteria \\
\hline Presence of at least 2 of the following within 30 days after HSCT: \\
\hline Bilirubin $>34 \mu \mathrm{mol} / \mathrm{L}(>2 \mathrm{mg} / \mathrm{dL})$ \\
\hline Hepatomegaly \\
\hline Ascites \\
\hline Unexplained weight gain $>5 \%$ \\
\hline According to Corbacioglu et al. (2012); Hematopoietic stem cell transplantation (HSCT) \\
\hline
\end{tabular}


Table 2

Characteristics of patients and donors

\begin{tabular}{|ll|}
\hline Characteristics & No. \\
\hline Patients (\%) & $105(100)$ \\
\hline Median age, years (range) & $8.6(0-26)$ \\
\hline Male (\%) & $61(58.1)$ \\
\hline Female (\%) & $44(41.9)$ \\
\hline Donors & \\
\hline Median age, years (range) & $28.5(0-54)$ \\
\hline Male (\%) & $63(60.0)$ \\
\hline Female (\%) & $42(40.0)$ \\
\hline Patients' diagnoses & $27(25.7)$ \\
\hline Acute lymphoblastic leukemia (\%) & $25(23.8)$ \\
\hline Acute myeloid leukemia (\%) & $14(13.3)$ \\
\hline Myelodysplastic syndrome (\%) & $2(1.9)$ \\
\hline Lymphoma (\%) & $12(11.4)$ \\
\hline Solid tumor (\%) & $25(23.8)$ \\
\hline Genetic disease (\%) & $31(29.5)$ \\
\hline Stem cell source & \\
\hline Bone marrow (\%) & $52(49.5)$ \\
\hline Peripheral blood (\%) & \\
\hline Type of donors & $17.3)$ \\
\hline HLA-compatible unrelatad (\%) & \\
\hline HLA-mismatched unrelated (\%) & \\
\hline HLA-haploidentical related (\%) & \\
\hline HLA-identical related (\%) & \\
\hline Number (No.); Human leukocyte antigen (HLA) \\
\hline
\end{tabular}


Table 3

Univariate analysis of transplantation-related factors

\begin{tabular}{|c|c|c|c|c|c|}
\hline Transplantation-related factors & No. & sos & OR & $95 \% \mathrm{Cl}$ & $p$ \\
\hline \multicolumn{6}{|l|}{ Busulfan } \\
\hline Yes & 45 & $8(17.8 \%)$ & 1.64 & $0.55-4.91$ & 0.376 \\
\hline No & 60 & $7(11.7 \%)$ & - & - & - \\
\hline \multicolumn{6}{|c|}{ Busulfan plus cyclophosphamide or melphalan } \\
\hline Yes & 31 & $5(16.1 \%)$ & 1.23 & $0.38-3.95$ & 0.764 \\
\hline No & 74 & $10(13.5 \%)$ & - & - & - \\
\hline \multicolumn{6}{|l|}{ Total body irradiation } \\
\hline Yes & 19 & $4(21.1 \%)$ & 1.82 & $0.51-6.48$ & 0.466 \\
\hline No & 86 & $11(12.8 \%)$ & - & - & - \\
\hline \multicolumn{6}{|l|}{ Stem cell source } \\
\hline Bone marrow & 74 & $13(17.6 \%)$ & 3.09 & $0.65-14.60$ & 0.221 \\
\hline Peripheral blood & 31 & $2(6.5 \%)$ & - & - & - \\
\hline \multicolumn{6}{|l|}{ Donor age } \\
\hline$\leq 28$ years & 46 & $9(19.6 \%)$ & 3.24 & $0.82-12.91$ & 0.082 \\
\hline$>28$ years & 43 & $3(7.0 \%)$ & - & - & - \\
\hline \multicolumn{6}{|l|}{ Donor sex } \\
\hline Female & 42 & $7(16.7 \%)$ & 1.38 & $0.46-4.13$ & 0.569 \\
\hline Male & 63 & $8(12.7 \%)$ & - & - & - \\
\hline \multicolumn{6}{|l|}{ HLA-mismatch } \\
\hline No & 67 & $10(14.9 \%)$ & 1.16 & $0.36-3.68$ & 0.804 \\
\hline Yes & 38 & $5(13.2 \%)$ & - & - & - \\
\hline $\begin{array}{l}\text { Number (No.); Sinusoidal obstru } \\
\text { Human leukocyte antigen (HLA) }\end{array}$ & he $(\mathrm{S}$ & ; Odds ratio ( & Co & lence interva & \\
\hline
\end{tabular}


Table 4

Univariate analysis of patient-related factors

\begin{tabular}{|c|c|c|c|c|c|}
\hline Patient-related factors & No. & sos & OR & $95 \% \mathrm{Cl}$ & $p$ \\
\hline \multicolumn{6}{|l|}{ Patient age } \\
\hline$<1$ year & 6 & $3(50.0 \%)$ & 7.25 & $\begin{array}{l}1.31- \\
40.10\end{array}$ & 0.037 \\
\hline$\geq 1$ year & 99 & $12(12.1 \%)$ & - & - & - \\
\hline \multicolumn{6}{|l|}{ Patient sex } \\
\hline Female & 44 & $7(15.9 \%)$ & 1.25 & $0.42-3.76$ & 0.686 \\
\hline Male & 61 & $8(13.1 \%)$ & - & - & - \\
\hline \multicolumn{6}{|c|}{ Gemtuzumab ozogamicin } \\
\hline Yes & 5 & $3(60.0 \%)$ & 11.00 & $\begin{array}{l}1.67- \\
72.68\end{array}$ & 0.020 \\
\hline No & 100 & $12(12.0 \%)$ & - & - & - \\
\hline \multicolumn{6}{|l|}{ Aspartate transaminase } \\
\hline$>1 \mu \mathrm{mol} / \mathrm{L}^{* \mathrm{~s}}$ & 10 & $2(20.0 \%)$ & 1.48 & $0.28-7.83$ & 0.643 \\
\hline$\leq 1 \mu \mathrm{mol} / L^{*} \mathrm{~s}$ & 83 & $12(14.5 \%)$ & - & - & - \\
\hline \multicolumn{6}{|l|}{ Alanin transaminase } \\
\hline$>1 \mu \mathrm{mol} / \mathrm{L}^{*} \mathrm{~s}$ & 28 & $5(17.9 \%)$ & 1.46 & $\begin{array}{l}0.78- \\
10.89\end{array}$ & 0.538 \\
\hline$\leq 1 \mu \mathrm{mol} / \mathrm{L}^{*} \mathrm{~s}$ & 77 & $10(13.0 \%)$ & - & - & - \\
\hline \multicolumn{6}{|l|}{ Cholinesterase } \\
\hline$<90 \mu \mathrm{mol} / \mathrm{L}^{*} \mathrm{~s}$ & 21 & $5(23.8 \%)$ & 1.80 & $0.51-6.30$ & 0.497 \\
\hline$\geq 90 \mu \mathrm{mol} / \mathrm{L}^{*} \mathrm{~s}$ & 54 & $8(14.8 \%)$ & - & - & - \\
\hline \multicolumn{6}{|l|}{ Glutamyl transpeptidase } \\
\hline$\leq 0,5 \mu \mathrm{mol} / \mathrm{L}^{* \mathrm{~s}}$ & 44 & $9(20.5 \%)$ & 2.11 & $0.65-6.88$ & 0.210 \\
\hline$>0,5 \mu \mathrm{mol} / \mathrm{L}^{*} \mathrm{~s}$ & 46 & $5(10.9 \%)$ & - & - & - \\
\hline \multicolumn{6}{|l|}{ Lactate dehydrogenase } \\
\hline$>5 \mu \mathrm{mol} / \mathrm{L}^{*} \mathrm{~S}$ & 9 & $2(22.2 \%)$ & 1.78 & $0.33-9.52$ & 0.616 \\
\hline$\leq 5 \mu \mathrm{mol} / \mathrm{L}^{*} \mathrm{~s}$ & 94 & $13(13.8 \%)$ & - & - & - \\
\hline
\end{tabular}

Number (No.); Sinusoidal obstruction syndrome (SOS); Odds ratio (OR); Confidence interval (CI) 


\begin{tabular}{|c|c|c|c|c|c|}
\hline Patient-related factors & No. & sos & OR & $95 \% \mathrm{Cl}$ & $p$ \\
\hline \multicolumn{6}{|l|}{ Alkaline phosphatase } \\
\hline$>3 \mu \mathrm{mol} / \mathrm{L}^{\star} \mathrm{s}$ & 13 & $4(30.8 \%)$ & 3.38 & $\begin{array}{l}0.88- \\
13.03\end{array}$ & 0.085 \\
\hline$\leq 3 \mu \mathrm{mol} / \mathrm{L}^{*} \mathrm{~s}$ & 86 & $10(11.6 \%)$ & - & - & - \\
\hline \multicolumn{6}{|l|}{ Ferritin } \\
\hline$>2400 \mathrm{ng} / \mathrm{mL}$ & 37 & $11(29.7 \%)$ & 5.29 & $\begin{array}{l}1.53- \\
18.25\end{array}$ & 0.005 \\
\hline$\leq 2400 \mathrm{ng} / \mathrm{mL}$ & 54 & $4(7.4 \%)$ & - & - & - \\
\hline \multicolumn{6}{|l|}{ Ferritin } \\
\hline$>2000 \mathrm{ng} / \mathrm{mL}$ & 47 & $12(25.5 \%)$ & 4.69 & $\begin{array}{l}1.22- \\
17.95\end{array}$ & 0.016 \\
\hline$\leq 2000 \mathrm{ng} / \mathrm{mL}$ & 44 & $3(6.8 \%)$ & - & - & - \\
\hline \multicolumn{6}{|l|}{ Ferritin } \\
\hline$>1500 \mathrm{ng} / \mathrm{mL}$ & 50 & $12(24.0 \%)$ & 4.00 & $\begin{array}{l}1.05- \\
15.32\end{array}$ & 0.033 \\
\hline$\leq 1500 \mathrm{ng} / \mathrm{mL}$ & 41 & $3(7.3 \%)$ & - & - & - \\
\hline \multicolumn{6}{|l|}{ Albumin } \\
\hline$<30 \mathrm{~g} / \mathrm{L}$ & 62 & $9(14.5 \%)$ & 1.02 & $0.33-3.11$ & 0.974 \\
\hline$\geq 30 \mathrm{~g} / \mathrm{L}$ & 42 & $6(14.3 \%)$ & - & - & - \\
\hline \multicolumn{6}{|l|}{ Total bilirubin } \\
\hline$>17 \mu \mathrm{mol} / \mathrm{L}$ & 28 & $5(17.9 \%)$ & 1.46 & $0.45-4.71$ & 0.538 \\
\hline$\leq 17 \mu \mathrm{mol} / \mathrm{L}$ & 77 & $10(13.0 \%)$ & - & - & - \\
\hline \multicolumn{6}{|l|}{ C-reactive protein } \\
\hline$>18 \mathrm{mg} / \mathrm{L}$ & 40 & $8(20.0 \%)$ & 2.07 & $0.69-6.24$ & 0.189 \\
\hline$\leq 18 \mathrm{mg} / \mathrm{L}$ & 65 & $7(10.8 \%)$ & - & - & - \\
\hline \multicolumn{6}{|c|}{ International normalized ratio } \\
\hline$\geq 1,3$ & 16 & $6(37.5 \%)$ & 5.91 & $\begin{array}{l}1.65- \\
21.19\end{array}$ & 0.009 \\
\hline$<1,3$ & 76 & $7(9.2 \%)$ & - & - & - \\
\hline
\end{tabular}


Table 5

Multivariate analysis of risk factors

\begin{tabular}{|lccc|}
\hline Risk factors in multivariate analysis & OR & $\mathbf{9 5 \%} \mathbf{C l}$ & $\boldsymbol{p}$ \\
\hline Gemtuzumab ozogamicin & 9.24 & $1.02-83.55$ & $\mathbf{0 . 0 4 8}$ \\
\hline Ferritin $>\mathbf{2 4 0 0 ~} \mathbf{n g} / \mathrm{mL}$ & 5.74 & $1.27-26.04$ & $\mathbf{0 . 0 2 3}$ \\
\hline INR $\geq \mathbf{1 . 3}$ & 8.02 & $1.77-36.43$ & $\mathbf{0 . 0 0 7}$ \\
\hline Odds ratio (OR); Confidence interval (Cl); International normalized ratio (INR) \\
\hline
\end{tabular}

Figures

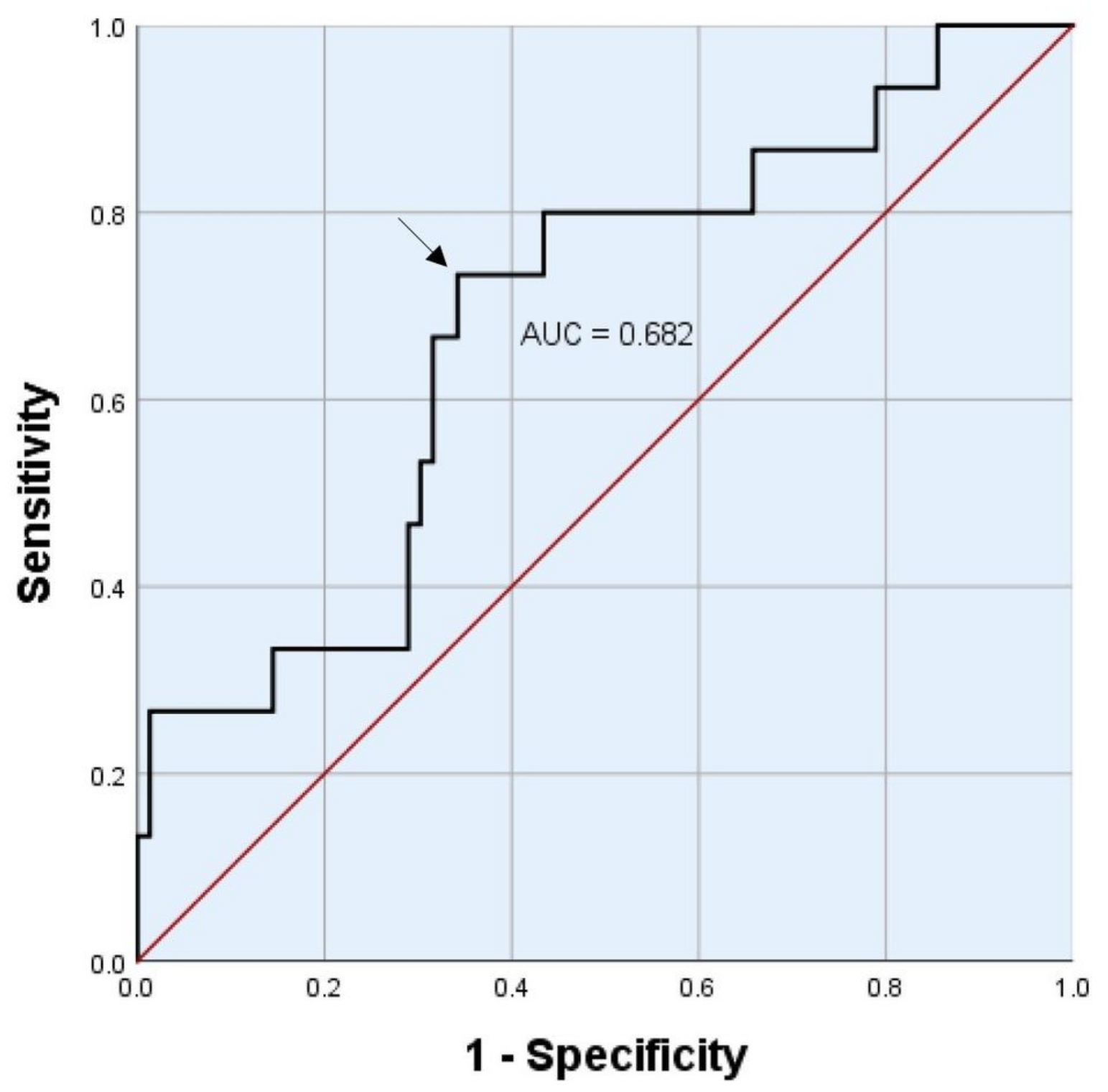




\section{Figure 1}

Receiver operating characteristic curve of different ferritin cutoffs Best ferritin cutoff is marked with an arrow (2420.15 ng/mL); Area under the curve (AUC) 